\section{The dissolution of mono- sodium urate monohydrate crystals: formulation of a biocompatible buffer solution with potential use in the treatment of gouty arthropathies}

\author{
Gabriella Tamasi, ${ }^{1}$ Renzo Cini, ${ }^{1}$ \\ Michele Gregorkiewitz, ${ }^{2}$ Sauro Lorenzini, ${ }^{3}$ \\ Roberto Marcolongo, ${ }^{4}$ Giovanni Cavallo ${ }^{5}$ \\ 1 Department of Chemistry and \\ 2Department of Earth Sciences, \\ University of Siena, Siena; ${ }^{3}$ Department \\ of Clinical Medicine and Immunological \\ Sciences, Rheumatology Section, \\ University of Siena, Policlinico Le Scotte, \\ Siena; ${ }^{4}$ Center of Biochemical and Clinical \\ Studies on Rheumatic Diseases, \\ University of Siena, Siena; 5Italdevice srl, \\ Pomezia, Italy
}

\section{Abstract}

The dissolving abilities (DAs) of several aqueous media for microcrystalline monosodium urate monohydrate (MSU, $\mathrm{NaC}_{5} \mathrm{~N}_{4} \mathrm{O}_{3} \mathrm{H}_{3} \cdot \mathrm{H}_{2} \mathrm{O}$ ) have been investigated using UV spectrophotometry for quantitative analytical determinations and X-ray diffraction, scanning electron microscopy and polarized light optical microscopy to assess structural aspects. High DAs were found for a buffer labeled TMT which contains tris(hydroxymethyl)aminomethane (TRIS), tris(hydroxymethyl)aminomethane hydrochloride (TRIS·HCl), D-mannitol (MAN) and taurine (TAU) and gave $\mathrm{DA}_{30}=1298(5) \mathrm{mg} / \mathrm{L}$ for synthetic MSU after 30 min incubation at $37^{\circ} \mathrm{C}$ and $\mathrm{pH} 7.4$, most of the dissolution taking place within the first 5-10 min. Semiempirical molecular modelling techniques (ZIND0/1) show a favorable energy balance for the formation of a TRIS-urate-TRIS adduct which might explain the high DA values. Buffers containing linear or dendrimeric polyamines gave DA values which suggest that complex formation toward sodium cations is less important. An $e x$ vivo MSU sample was found to have a significantly lower $\mathrm{DA}$ value $\left(\mathrm{DA}_{30}=1124(5) \mathrm{mg} / \mathrm{L}\right.$ in TMT) as well as a lower crystallinity than its synthetic counterpart, possibly related to the presence of a non-crystalline impurity such as endogenous proteins. Cytotoxicity tests based on the MTT assay were used to check the biocompatibility of the TMT buffer and showed only moderate cell mortality after $24 \mathrm{~h}$ contact with the buffer solution.

\section{Introduction}

Biomineralizations are an important issue in arthropathies. One group of disorders, represented by chondrocalcinosis and pseudogout, are associated to calcium pyrophosphate dihydrate (CPPD, $\mathrm{Ca}_{2} \mathrm{P}_{2} \mathrm{O}_{7} \cdot 2 \mathrm{H}_{2} \mathrm{O}$ ) and hydroxylapatite ( $\left.\mathrm{HAP}, \mathrm{Ca}_{5}\left(\mathrm{PO}_{4}\right)_{3} \mathrm{OH}\right)$, which deposit in the cartilage and soft tissue around the joint, e.g. in the synovial membrane. ${ }^{1,2}$ CPPD forms slowly and is found in many elderly individuals ( $\sim 40 \%$ at age 80 and older).,34 The crystals, usually small $(\leq 5 \mu \mathrm{m})$ and of compact shape, contribute to various degenerative processes. In some instances, e.g. due to trauma, the crystals may also cause inflammation (pseudogout), usually through lysis of neutrophil polymorphonuclear (PMN) leukocytes which phagocytize freely suspended crystals in the synovial cavity.

Beyond symptomatic treatment of the inflammation, e.g. by oral medication with non-steroidal anti-inflammatory drugs (NSAIDs), a method for the removal of the crystals themselves has recently been proposed, based on joint lavage with Ca-complexing buffer solutions, ${ }^{5}$ that seems interesting to prevent pseudogout attacks and mitigate some of the degeneration processes due to crystal deposits.

A quite different situation is found in gout, which develops in the presence of monosodium urate monohydrate crystals (MSU, 2,6,8trioxopurinate $\left(-\mathrm{H}^{3}\right)$ sodium salt monohydrate, $\mathrm{NaC}_{5} \mathrm{~N}_{4} \mathrm{O}_{3} \mathrm{H}_{3} \cdot \mathrm{H}_{2} \mathrm{O}$, Figure 1).

In contrast to the phosphates above, MSU is not an ionic, but a van der Waals solid, i.e. the bonds between the single ions or molecules are much weaker and the crystal easily undergoes plastic deformation. The soft MSU crystals can therefore hardly be responsible for a mechanical degeneration of the joint, but they may still provoke inflammation (gout) in a similar way as described above. Another peculiarity of MSU is that its formation is clearly related to high levels of urate in the blood serum (uricemia) but, although necessary, this condition is not sufficient to provoke gout, either because crystallization in the synovial liquid may be inhibited or because the crystals are somehow blocked to develop their pathogenic actions. ${ }^{6,7}$ Much ongoing research is concerned with these facts and it seems that surface covering of crystal faces may play a role, ${ }^{8-11}$ but the therapy of gout is so far restricted to the symptomatic treatment of the inflammation itself and to the prevention of urate crystal formation through the control of uricemia, either reducing the urate production from purine (e.g. using xanthine oxidase inhibitors) or increasing the rate of uric acid elimination (e.g. using uricosuric drugs). ${ }^{12}$

While the systemic treatment of uricemia is
Correspondence: Gabriella Tamasi, Department of Chemistry, University of Siena, via A. Moro 2, 53100 Siena, Italy.

Tel. +39.0577.234368 - Fax +39.0577.234254

E-mail tamasi@unisi.it

Key words: arthritis, urate, TRIS buffer, crystallinity, biomineralization.

Acknowledgements: the authors would thank University of Siena for funding, and Dr. Marta Bellini for part of the UV spectrophotometric measurements which have been made during her internship for the Tesi di Laurea in Chimica at Department of Chemical and Biosystem Sciences and Technologies, University of Siena.

Contributions: GT, dissolving ability and molecular modeling studies; RC, dissolving ability and molecular modeling studies; MG, X-ray crystallography and crystal morphology studies; SL, toxicity test in vitro; RM, critical interpretation of data; $\mathrm{GC}$, possible therapeutic applications.

Conflict of interests: the authors declare no potential conflict of interests.

Received for publication: 28 September 2011. Revision received: 5 July 2012.

Accepted for publication: 23 July 2012.

This work is licensed under a Creative Commons Attribution NonCommercial 3.0 License (CC BYNC 3.0).

(C) Copyright G.Tamasi et al., 2013

Licensee PAGEPress, Italy

Rheumatology Reports 2013; 5:e4

doi:10.4081/rr.2013.e4

efficient to prevent urate crystal formation, the removal of the crystals, once they have formed, remains a problem. The systemic approach is in principle possible because urate would spontaneously diffuse from the synovial fluid (concentrated compartment) to the blood plasma (diluted compartment) until both compartments have the same concentration, insufficient to reach the solubility product of MSU crystal formation. However, this diffusional process takes place through a quite limited membrane area defined by the blood capillaries at the inner wall of the synovial membrane and it would take 3 months to 3 years to dissolve MSU crystal deposits in this way. ${ }^{13}$

In search for an alternative, the present study is aimed at finding a suitable buffer solution for the direct dissolution of the MSU deposits through joint lavage. Beside the dissolving ability of the different chemical agents which can be added to the buffer and may specifically sequester either sodium (dendrimers etc.) or the urate anion (hydrogenbridge formers), particular attention has been 
paid to biocompatibility in terms of $\mathrm{pH}$, osmolality and cytotoxicity as well as to the changes in morphology and microstructure of the crystals during dissolution. The study was conducted on synthetic and ex vivo MSU crystals.

\section{Materials and Methods}

\section{Materials}

Crystals of sodium hydrogen urate monohydrate (2,6,8-trioxopurinate $\left(-\mathrm{H}^{3}\right)$ sodium salt monohydrate, MSU, $\mathrm{NaC}_{5} \mathrm{~N}_{4} \mathrm{O}_{3} \mathrm{H}_{3} \cdot \mathrm{H}_{2} \mathrm{O}$, $\mathrm{MM}=208.11 \mathrm{~g} / \mathrm{mol}$, Figure 1) were analytical grade, a.g., from Sigma, Milan. Tris(hydroxymethyl)aminomethane (1,3-dihydroxy-2hydroxymethyl-2-aminopropane, TRIS, $\mathrm{C}_{4} \mathrm{H}_{11} \mathrm{NO}_{3}$ ), TRIS.HCl, D-mannitol (D-2,3,4,5,6pentahydroxy-hexan-1-ol, MAN, $\mathrm{C}_{6} \mathrm{H}_{14} \mathrm{O}_{6}$ ) and taurine (2-amino-ethansulfonic acid, TAU, $\mathrm{C}_{2} \mathrm{H}_{7} \mathrm{NO}_{3} \mathrm{~S}$ ) were from Carlo Erba, Milan. Spermine (1,12-diamino-4,9-diaza-dodecane, SPE, $\mathrm{C}_{10} \mathrm{H}_{26} \mathrm{~N}_{4}$ ) was from Fluka, Basel. Polyamidoamine (N,N,N',N'-(3-one-4-aza-6amino-hexyl)-1,2-diaminoethane, PAMAM, $\mathrm{C}_{22} \mathrm{H}_{48} \mathrm{~N}_{10} \mathrm{O}_{4}$ ), tetrazolium salt (3-[4,5dimethylthiazol-2-yl]-2,5-diphenyltetrazolium bromide, MTT, $\mathrm{C}_{18} \mathrm{H}_{16} \mathrm{~N}_{5} \mathrm{SBr}$ ) and Dulbecco's modified Eagle's medium (DMEM) were from Sigma, Milan. $\mathrm{NaCl}, \mathrm{KCl}, \quad \mathrm{KH}_{2} \mathrm{PO}_{4}$, $\mathrm{Na}_{2} \mathrm{HPO}_{4} \cdot 12 \mathrm{H}_{2} \mathrm{O}$ (PBS buffer) were a.g. from Carlo Erba, Milan. All reagents have been used as purchased without further purification. In addition to the synthetic reagents, MSU was also used in form of ex vivo crystals obtained from tophaceous subcutaneous deposits and on ex vivo crystal suspensions in synovial fluid aspirated from an acute inflamed knee.

\section{Dissolving ability}

Synthetic crystals (12 mg, stored at room temperature, $22(1)^{\circ} \mathrm{C}$, in ambient air atmosphere) were incubated in $5 \mathrm{~mL}$ of the dissolving solutions at $\mathrm{pH}$ 7.4(1) (pH-Meter E603, Metrohm), osmolality 290(10) m0sm (Osmostat, DIC) and $37^{\circ} \mathrm{C}$ for different incubation times (1-60 min), under stirring (numbers in parentheses give the estimated standard deviations and are referred to the last digits). The dissolving solution was, in most cases, either TM, which consists of a TRIS buffer (TRIS·HCl $5.72 \mathrm{~g} / \mathrm{L}$, TRIS $1.66 \mathrm{~g} / \mathrm{L}$ ) ${ }^{14}$ containing MAN (36 g/L), or TMT, which stands for TM plus TAU $(3 \mathrm{~g} / \mathrm{L})$.

Further dissolution tests were performed using the following alternative formulations: deionized water with diluted $\mathrm{NaOH}$ to reach $\mathrm{pH}$ 7.4 (5 m0sm), aqueous $\mathrm{NaCl}$ (8 g/L), TRIS buffer alone $(80 \mathrm{m0sm})$, PAMAM $(2.38 \mathrm{~g} / \mathrm{L})$ with $\mathrm{HCl}$ to reach $\mathrm{pH} 7.4$ (33 $\mathrm{m0sm}), \mathrm{SPE}$ (2.38 $\mathrm{g} / \mathrm{L})$ and $\mathrm{HCl}$ to reach $\mathrm{pH} 7.4$ (34 m0sm), SPE

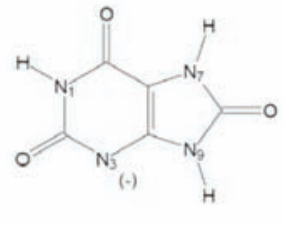

$\mathrm{Na}^{*} \mathrm{H}_{2} \mathrm{O}$

MSU, $\mathrm{NaC}_{5} \mathrm{H}_{3} \mathrm{~N}_{4} \mathrm{O}_{3} \cdot \mathrm{H}_{2} \mathrm{O} ; \mathrm{Mw}, 208.1$
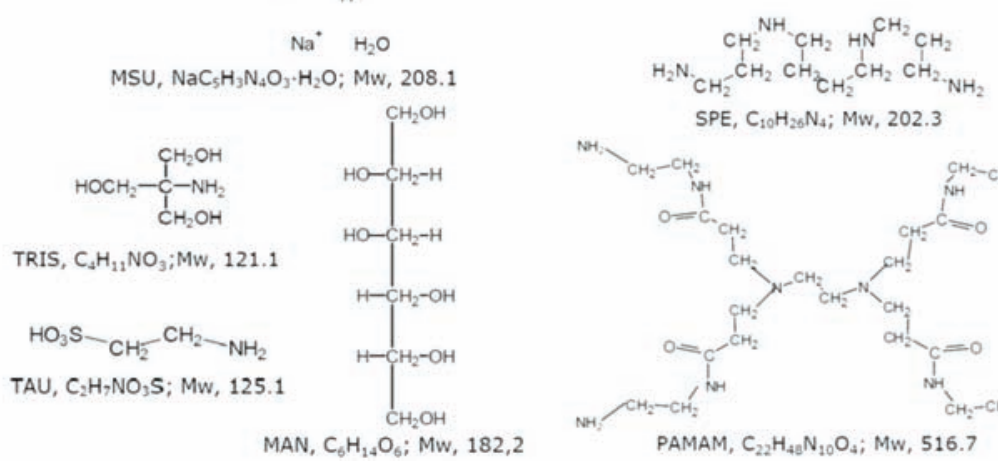

$\mathrm{SPE}, \mathrm{C}_{10} \mathrm{H}_{26} \mathrm{~N}_{4} ; \mathrm{Mw}, 202.3$

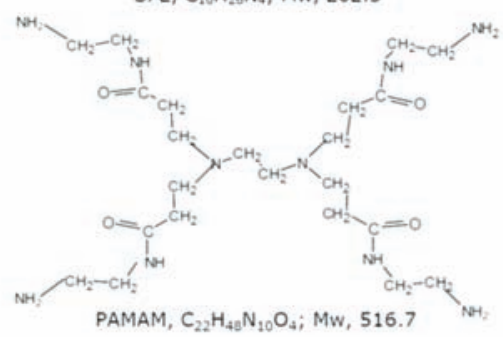

Figure 1. Drawings of selected chemical species used in this work.

$(2.38 \mathrm{~g} / \mathrm{L})$ with MAN $(50 \mathrm{~g} / \mathrm{L})$ and $\mathrm{HCl}$ to reach pH 7.4 (309 m0sm), PBS ( $\mathrm{NaCl} 8 \mathrm{~g} / \mathrm{L}, \mathrm{KCl} 0.2$ $\mathrm{g} / \mathrm{L}, \mathrm{Na}_{2} \mathrm{HPO}_{4} \cdot 12 \mathrm{H}_{2} \mathrm{O} 2.87 \mathrm{~g} / \mathrm{L}, \mathrm{KH}_{2} \mathrm{PO}_{4} 0.2 \mathrm{~g} / \mathrm{L}$; $\mathrm{pH} 7.4,300 \mathrm{mOsm}), \mathrm{PBS}$ without $\mathrm{NaCl}$ (27 m0sm), PBS with SPE (2.38 g/L, $334 \mathrm{m0sm})$, PBS without $\mathrm{NaCl}$ and with SPE $(2.38 \mathrm{~g} / \mathrm{L}, 61$ $\mathrm{mOsm}), \mathrm{NaCl}(8 \mathrm{~g} / \mathrm{L})$ with SPE $(2.38 \mathrm{~g} / \mathrm{L}, 334$ m0sm). After incubation, the mixtures were filtered using syringes equipped with a surfactant-free cellulose acetate membrane filter (Schleicher \& Schuell, disk diameter $30 \mathrm{~mm}$, mean pore diameter $0.22 \mu \mathrm{m})$. The determination of DA values for MSU was carried out, in the clear filtrates, via UV spectrophotometry (Perkin Elmer-Model EZ-201 spectrophotometer) at $\lambda=291.0 \mathrm{~nm}$.

\section{X-ray crystallography}

X-ray powder diffraction patterns were collected for the different samples of MSU in order to check their crystallographic identity, phase purity and grain size before and after solution treatment. An automated Philips PW1710 powder diffractometer with BraggBrentano geometry was used in combination with $\operatorname{CuK} \alpha(\lambda=1.54060 \AA)$ radiation and a graphite monochromator. Optical slit and scan parameters were: in plane divergence $1^{\circ}$, receiving slit $0.2 \mathrm{~mm}$, step size/time $0.04^{\circ} 20 / 2 \mathrm{~s}$. Peak widths in terms of FWHM were obtained from a single peak curve fitting procedure and used to estimate the apparent grain size $\varepsilon$ following the Scherrer equation and allowing for a correction term which accounts for the instrumental contribution to the peak width. ${ }^{15}$

\section{Crystal morphology}

A scanning electron microscope (SEM,
Philips XL30, acceleration voltage $20 \mathrm{kV}$ ) equipped with an energy dispersive fluorescent X-ray detector (EDAX DX4) for elemental analysis $(\mathrm{Z} \geq 6)$ was used to assess morphology and composition of ex vivo MSU samples and their synthetic counterparts before and after solution treatment. The samples were mounted on Al-holders and metallized in a graphite evaporator (Balzers CED 020, $50 \mathrm{~Pa}$ ), which allows for EDAX analysis of all possible elements heavier than carbon.

For polarized light optical microscopy observations of the crystals and their dissolution behavior in the buffer, a polarizing microscope (Leica DMLSP) permitting $360^{\circ}$ azimuthal sample rotation was used. A suspension of MSU crystals was placed in a closed cuvette at temperatures from 20 to $50^{\circ} \mathrm{C}$, and pictures were taken at time intervals with a CCD camera system (JVC-TK-C1380) directly coupled to the microscope photo tube exit.

\section{Toxicity test in vitro}

Measurements of cellular vitality have been performed on chondrocytes and synovial cells. The cells were obtained from three patients with hip osteoarthritis undergoing surgery for total hip prostheses. Chondrocyte and synoviocyte cultures were obtained using the method described in Cini et al. ${ }^{5}$

Cells were then incubated with varying concentrations of TRIS.HCI/TRIS and D-mannitol (TM) as well as the typical (see above) concentration of TRIS.HCI/TRIS, D-mannitol and taurine (TMT) for 24 hours at $37^{\circ} \mathrm{C}$. The control culture was obtained by incubating cells with Dulbecco's modified Eagle's medium without foetal calf serum for 24 hours. Cytotoxicity was determined two days after exposure to TM and 
TMT using the MTT assay, ${ }^{16}$ which measures the number of metabolically active cells by a colorimetric technique. In the case of TRIS $\cdot \mathrm{HCl}+\mathrm{TRIS}+\mathrm{MAN}+\mathrm{TAU} \quad(5.72+1.66+$ $36.00+3.00 \mathrm{~g} / \mathrm{L})$ toxicity experiments were performed also at $0.5,2.0,4.0,12.0 \mathrm{~h}$.

\section{Structure simulations and adduct formation energies}

For uric acid, the urate anion in its four possible configurations with respect to deprotonation $\left(\mathrm{H}^{1}, \mathrm{H}^{3}, \mathrm{H}^{7}, \mathrm{H}^{9}\right)$, the TRIS ligand and the TRIS-urate and TRIS-uric acid systems, calculations were made applying molecular orbital semi-empirical AM1 ${ }^{17}$ and ZIND0/1 ${ }^{18}$ methods as well as molecular mechanics MM using a MM2-type force field ${ }^{19}$ in order to identify the most stable structures and to get an estimate of the corresponding adduct formation energies, normally in the gaseous state and in some cases also in presence of solvent (water) as simulated via a continuum field (in MM calculations). Calculations have been performed using the HyperChem 5.1 (for AM1 and ZINDO/1) ${ }^{20}$ and MacroModel 6.0 (for MM) ${ }^{21}$ program systems, graphic representations have been obtained using ORTEP-3.22

\section{Results}

\section{Dissolving ability values}

Most dissolution experiments were conducted using synthetic MSU crystals. The highest DA values were obtained using the TRIS+MAN, TM, mixture which gave, after 30 min incubation, $\mathrm{DA}_{30}=1303(5) \mathrm{mg} / \mathrm{L}$ (Table 1 and Figure 2).

Addition of TAU to the buffer (TRIS+MAN+TAU, TMT) has little influence on the dissolving ability and shows $\mathrm{DA}_{30}=1298(5) \mathrm{mg} / \mathrm{L}$. It has to be noted that crystal dissolution happens mostly during the first 5-10 min incubation time. In fact, DA values after $5,10,30,60 \mathrm{~min}$ incubation at $37^{\circ} \mathrm{C}$ are 1217(5), 1241(5), 1298(5), 1298(5) mg/L, respectively (Figure $2 \mathrm{~A}$ ).

The DA values measured for pure water are somewhat smaller than those for TM and TMT, but still relatively high with $\mathrm{DA}_{30}=1146(5)$ $\mathrm{mg} / \mathrm{L}$ at $\mathrm{pH}$ 7.4. The datum is in agreement with earlier findings ${ }^{8,23.24}$ and shows that water is, in principle, an effective dissolving agent. Its use is, however, precluded for in vivo applications because of its poor buffer capacity and the low osmolality. In the case of PBS both the buffering ability and the osmolality (300 $\mathrm{m0sm}$ ) would be suitable for in vivo treatments but the dissolving ability was found to be very poor, $\mathrm{DA}_{30}=85(5) \mathrm{mg} / \mathrm{L}$, in agreement with Wang et al. ${ }^{24}$

The reason for the decreased effectiveness is the common ion $\left(\mathrm{Na}^{+}\right)$effect, $\mathrm{PBS}$ being rich in sodium chloride $(8 \mathrm{~g} / \mathrm{L})$. In the case $\mathrm{NaCl}$ is removed from PBS ( $27 \mathrm{mOsm}$ ), $\mathrm{DA}_{30}$ increases up to $592(5) \mathrm{mg} / \mathrm{L}$ (it has to be recalled that sodium ions are still present due to the presence of $\mathrm{Na}_{2} \mathrm{HPO}_{4} \cdot 12 \mathrm{H}_{2} \mathrm{O}$ ).

Additional tests were performed to check the alkali ion and urate ion complexing power of linear amines or dendrimers. In the case the system contains SPE (pH 7.4, $34 \mathrm{mOsm}$ ), the dissolving efficiency is again high, $\mathrm{DA}_{30}=1359(5) \mathrm{mg} / \mathrm{L}$. The addition of MAN to adjust the osmolality of the buffer to 309 m0sm gives a small increase in effectiveness,

Table 1. Dissolving ability (DA) values (mg/L) for synthetic MSU crystals (12 mg) obtained by using TRIS+MAN, TM, and TRIS+MAN+TAU, TMT, aqueous buffer solutions $\left(5 \mathrm{~mL}, 37^{\circ} \mathrm{C}, \mathrm{pH} 7.4,290 \mathrm{mOsm}\right)$, at different incubation times $\mathrm{t}(\mathrm{min})$. Estimated standard deviations are $5 \mathrm{mg} / \mathrm{L}$ as calculated from averaging over multiple determinations.

\begin{tabular}{|c|c|c|c|c|}
\hline \multirow{2}{*}{$\mathrm{t} / \mathrm{min}$} & \multicolumn{2}{|c|}{ DA (mg/L) } & \multicolumn{2}{|c|}{ Fraction (\%) of MSU dissolved* } \\
\hline & TM & TMT & TM & TMT \\
\hline 5 & 1241 & 1217 & 51.7 & 50.7 \\
\hline 8 & 1265 & 1241 & 52.7 & 51.7 \\
\hline 10 & 1279 & 1260 & 53.3 & 52.5 \\
\hline 15 & 1288 & 1284 & 53.7 & 53.5 \\
\hline 23 & 1298 & 1293 & 54.1 & 53.9 \\
\hline 30 & 1303 & 1298 & 54.3 & 54.1 \\
\hline 45 & 1307 & 1298 & 54.5 & 54.1 \\
\hline 60 & 1307 & 1298 & 54.5 & 54.1 \\
\hline
\end{tabular}

*These values depend on the total amount of MSU crystals used in the experiments. 50\% means that $6 \mathrm{mg}$ of the total of $12 \mathrm{mg}$ MSU per 5 $\mathrm{mL}$ have been dissolved. See text for explanation of the choice of $12 \mathrm{mg}$ for total amount of MSU in the DA measurements.
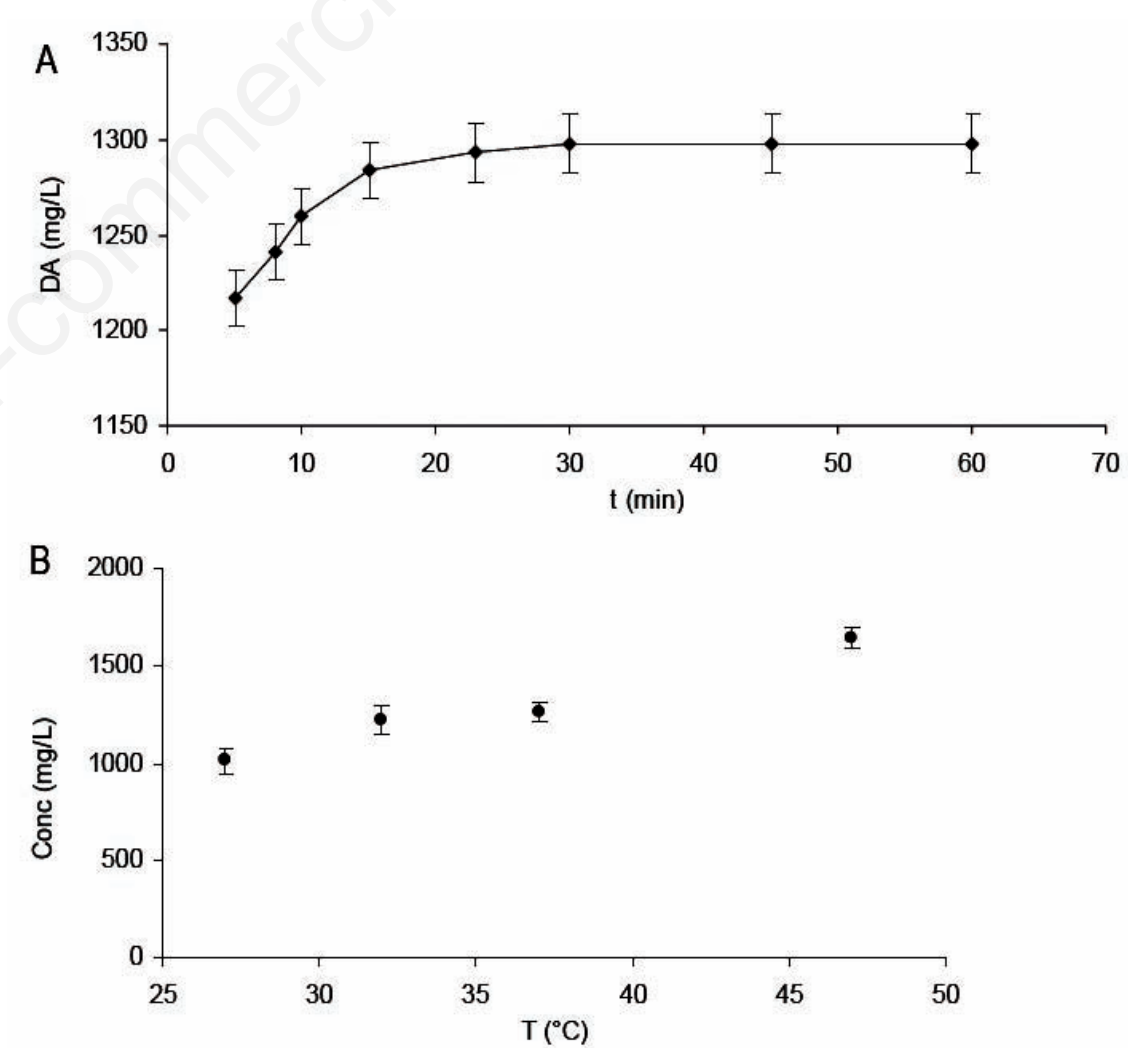

Figure 2. Dissolving ability values (mg/L) for synthetic MSU crystals (12 $\mathrm{mg})$ of TRIS+MAN+TAU, TMT, buffer solution ( $5 \mathrm{~mL}$, pH 7.4, osmolality $290 \mathrm{mOsm}$ ): A) as a function of time at $37^{\circ} \mathrm{C} ; \mathrm{B}$ ) as a function of temperature in the range $27-47^{\circ} \mathrm{C}$, after 30 min incubation time. 
Table 2. Cytotoxicity (CT) in terms of percent metabolically active cells as compared with controls measured by MTT assay. The results are expressed as mean of three separate experiments, estimated standard deviations are given in parenthesis. For the control cultures, cells were incubated in Dulbecco's modified Eagle's medium (DMEM) without foetal calf serum. All data were obtained after 24 hours of incubation. Toxicity data also at $0.5,2.0,4.0,12.0 \mathrm{~h}$ for TMT buffer are reported in square brackets.

\begin{tabular}{|c|c|c|c|c|c|}
\hline & $\begin{array}{l}\text { Control } \\
\text { DMEM }\end{array}$ & $\begin{array}{c}\text { TRIS } \cdot H C l+\text { TRIS + MAN } \\
5.72+1.66+36.00\end{array}$ & $\begin{array}{l}\text { Concentration }(\mathrm{g} / \mathrm{L}) \\
\text { TRIS.HCl+TRIS+MAN } \\
\mathbf{8 . 5 8}+2.49+23.60\end{array}$ & $\begin{array}{l}\text { Iffer components* } \\
\text { TRIS·HCl+ TRIS+MAN } \\
11.44+3.32+17.40\end{array}$ & $\begin{array}{c}\text { TRIS } \cdot H C l+T R I S+M A N+T A U \\
5.72+1.66+36.00+3.00\end{array}$ \\
\hline Synoviocytes & 100 & $65(1)$ & $46(5)$ & $30(3)$ & $67(12)[71(7), 65(7), 64(10), 71(12)]$ \\
\hline Chondrocytes & 100 & $55(6)$ & $52(3)$ & $38(7)$ & $57(5)[63(8), 63(9), 67(8), 65(6)]$ \\
\hline
\end{tabular}

*The buffer components were dissolved in aqueous solution where the ratio TRIS.HCl/TRIS defines pH 7.4 and the concentration of MAN was used to adjust the osmolality to a constant value (280-300 mOsm).

$\mathrm{DA}_{30}=1383(5) \mathrm{mg} / \mathrm{L}$. A less efficient behavior, with $\mathrm{DA}_{30}=1141(5) \mathrm{mg} / \mathrm{L}$, was found for the systems containing the dendrimeric molecule PAMAM (and $\mathrm{HCl}$ to reach $\mathrm{pH} 7.4$ ). In view of these results it seems that $\mathrm{H}$-donor/acceptor properties from the molecules in the dissolving media might explain the increase of solubility with respect to pure water. Some answers to this question will come from molecular modeling analysis (see below). It has to be noted that an ex vivo tophus taken from a gouty patient and consisting mainly of MSU, gave a concentration of 1124(5) mg/L in TMT buffer when 12 $\mathrm{mg}$ of solid were incubated in $5 \mathrm{~mL}$ at $37^{\circ} \mathrm{C}$ for $30 \mathrm{~min}$. This is considerably less than for synthetic MSU and might be important for the understanding of the crystallization mechanism of MSU (see discussion).

Finally the influence of temperature on dissolution of synthetic MSU was studied. On changing the temperature in the range 27$47^{\circ} \mathrm{C}$, the concentration of MSU in TMT (using $12 \mathrm{mg}$ of crystals, $5 \mathrm{~mL}$ of buffer, and incubation times of $10 \mathrm{~min}$ ) increases from 948(5) to 1644(5) $\mathrm{mg} / \mathrm{L}$ (Figure 2B). An approximate heat of dissolution of $4.9(3) \mathrm{kcal} / \mathrm{mol}$ (in TMT) could be computed from these data. A similar value $(5.5 \mathrm{kcal} / \mathrm{mol})$ can be calculated from data given by Allen et al. ${ }^{8}$ for the solution of monosodium urate in water. These values may be compared with the heats of dissolution for uric acid dihydrate where a much larger difference $(4.0 \mathrm{kcal} / \mathrm{mol}$ in TRIS buffer and 15.4 $\mathrm{kcal} / \mathrm{mol}$ in water) was found and attributed to the exothermic acid-base reaction $\mathrm{H}_{2} \mathrm{U}+\mathrm{TRIS} \rightarrow \mathrm{HU}^{-}+\mathrm{TRISH}^{+}$that occurs in the dissolution of uric acid. ${ }^{25}$

\section{Crystal structure and morphology}

X-ray diffraction patterns (Supplementary Figure 1) match with PDF Card \#31-1890 showing that all MSU samples are essentially phase pure materials having the triclinic structure reported in Mandel et al. ${ }^{26,27}$

The apparent grain size $\varepsilon$ estimated from the peak width is $520(120) \AA$ for the original synthetic MSU crystals prior and their residues after incubation in TMT (30 min), and 380(80) Å for MSU extracted from ex vivo gouty tophi.

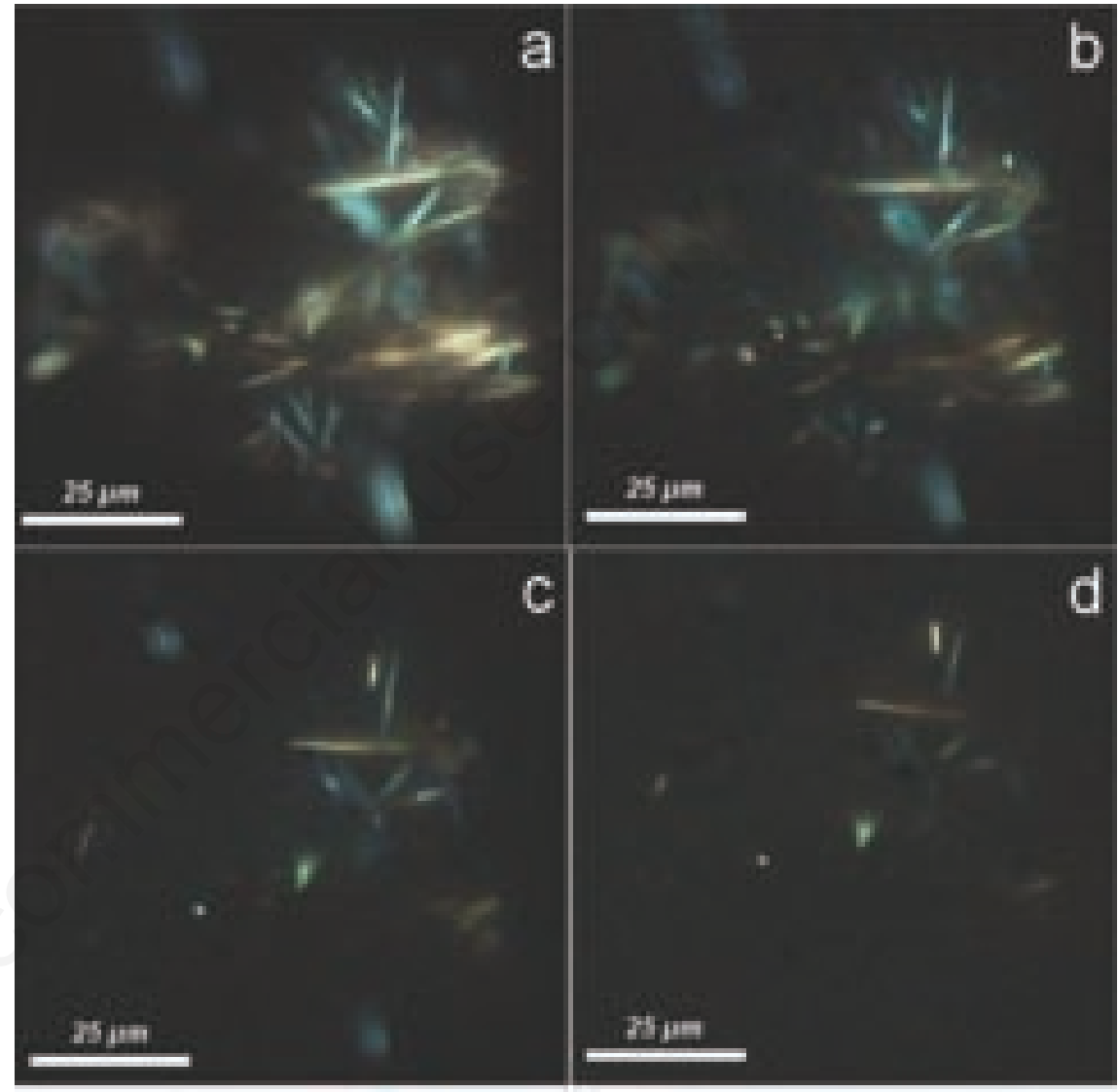

Figure 3. MSU crystals in TMT buffer solution at ca. $37^{\circ} \mathrm{C}$ after (A) $0,(\mathrm{~B}) 2$, (C) 3 and (D) 5 min. Polarizing microscope with crossed polarizers, inverted to negative.

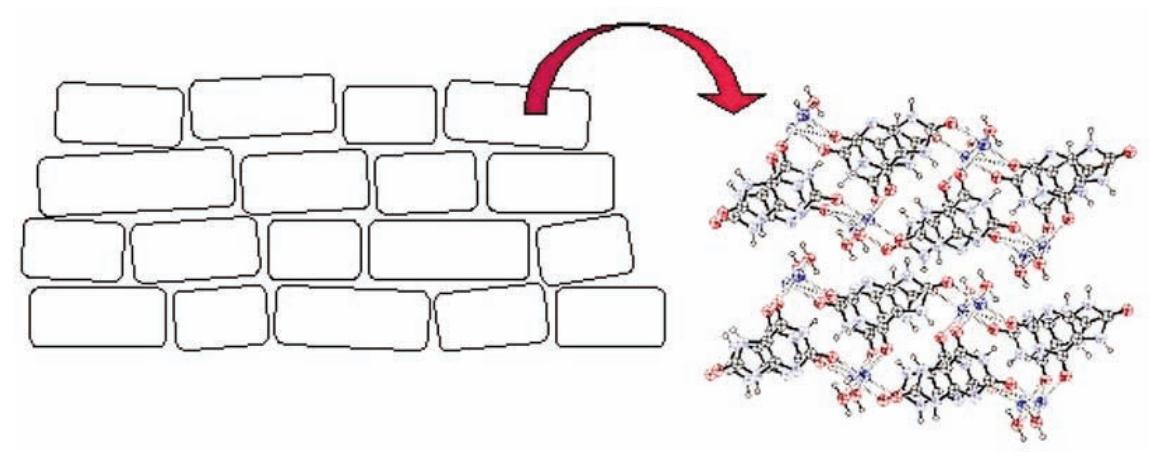

Figure 4. Schematic representation of the microstructure of an MSU crystal. 
Under the polarizing microscope, a MSU suspension of tophaceous deposits in synovial fluid showed crystals of about $5^{*} 15 \mu \mathrm{m}^{2}$ (Figure 3). At low temperature, these crystals did not dissolve appreciably during incubation periods up to about 30 min. Once the temperature was raised above $30^{\circ} \mathrm{C}$, dissolution became rapid and, without changing their acicular habit, many crystals disappeared within 5-10 min (Figure 3).

As can be seen from the scanning electron micrograph on Supplementary Figure 2, an apparent single crystal of $\sim 6^{*} 15 \mu \mathrm{m}^{2}$ is actually made up of many small laths, evidently the product of decomposition under electron beam bombardment. The thickness of these laths $(\sim 1000 \AA)$ comes near to the grain size estimated from diffraction peak broadening, i.e. the coherent domain size within which the crystal structure has no defects, and suggests that, in the real crystal, such submicroscopic domains are packed together forming a mosaic-like aggregate (Figure 4).

\section{Toxicity of dissolving media}

The results of cytotoxicity tests on human synoviocytes and chondrocytes at increasing overall concentrations ( $24 \mathrm{~h}$ incubation time) of TRIS (pH 7.4, 280-300 m0sm) are reported in Table 2 and indicate that the concentration of TRIS that corresponds to the highest DA values was also the less cytotoxic for cultured chondrocytes and fibroblast-like synoviocytes, with a percentage of metabolically active cells of 57(5) and 67(12), respectively. On increasing the concentration of TRIS.HCV/TRIS beyond $5.72 / 1.66 \mathrm{~g} / \mathrm{L}$, the toxicity of the buffer solution increases significantly, and for concentrations of $11.44 / 3.32 \mathrm{~g} / \mathrm{L}$ approximately one third only of the cells remain metabolically active. Toxicity measurements performed at $0.5,2.0$, $4.0,12.0 \mathrm{~h}$ for TMT buffer reveals that at ca $1 \mathrm{~h}$ incubation time (time requested for possible joint treatments) the toxicity for synoviocytes and chondrocytes is acceptably low.

\section{Molecular modeling and complex formation energies}

In an attempt to understand the dissolving abilities of the different solutions, the structure of urate, selected dissolving agents and possible adducts were studied using molecular modeling techniques. The structure of the hydrogen urate anion ( $\left.\mathrm{HU}^{-}\right)$was optimized both at the AM1 and the ZIND0/1 level. The latter level produced the better result as the simulated molecule was planar and computed distances and angles are in good agreement with experimental results from X-ray structure determination of MSU in the solid state (distances deviate less than $0.05 \AA$ excluding the $\mathrm{N}-\mathrm{H}$ deviations which average $0.09 \AA){ }^{27}$ Geometrical parameters are also in good agreement with the data obtained via density functional methods and reported in Chandra $e t$ $a l .{ }^{28}$ It is also noteworthy that the most stable optimized $\mathrm{HU}^{-}$anion, as computed at the gas phase, is deprotonated at $\mathrm{H}^{3}$ in agreement with the X-ray results. The standard formation enthalpies for the MSU anions are: HU--H1, 3117.86; HU--H ${ }^{3}$, -3138.77; $\mathrm{HU}^{-}-\mathrm{H}^{7},-3112.32$; HU--H ${ }^{9},-3132.77 \mathrm{kcal} / \mathrm{mol}$.

The structure of TRIS is flexible and several minima can be found on the conformational surface. The structure found in the solid state is close to one minimum energy structure (TRIS-A, Supplementary Table 1, Figure 5) found in the gas phase via ZINDO/1, ${ }^{29,30}$ but it is less stable than another one (TRIS-B, Figure 5) that has two strong intramolecular hydro- gen bonds by $15.77 \mathrm{kcal} / \mathrm{mol}$.

The molecular mechanics analysis for TRIS (gas phase) shows a minimum at $7.08 \mathrm{kcal} / \mathrm{mol}$ for total strain energy, which corresponds to a conformation similar to that found in the solid state. Other minima (with energy values by 5.22 and $4.66 \mathrm{kcal} / \mathrm{mol}$ ) could be found. These latter are characterized by intramolecular hydrogen bonds which lack in the conformation corresponding to the solid state structure. The computed formation energy (ZIND0/1) for a TRIS-HU--TRIS aggregate is -175.94 $\mathrm{kcal} / \mathrm{mol}$, without any solvation effect. This is a quite large energy which lies clearly beyond the difference between the energies of the various conformations of TRIS alone and has its origin in the cooperative effect of several

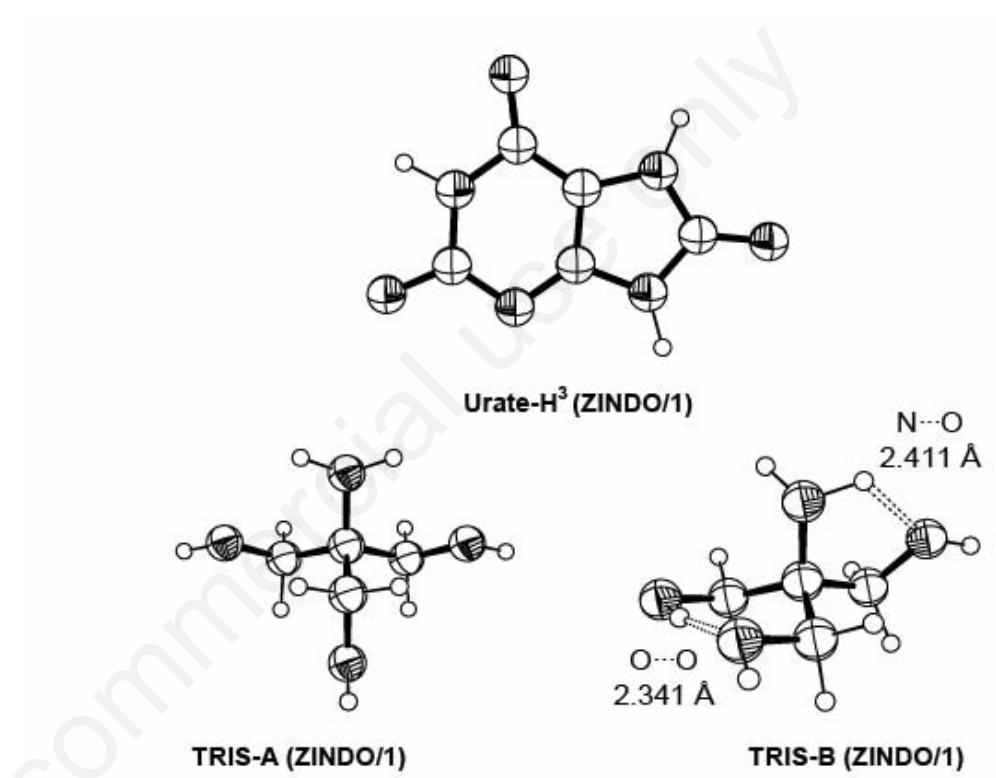

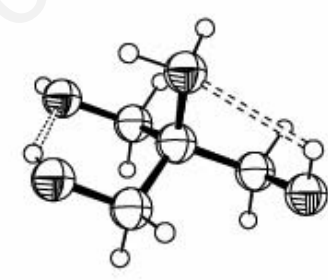

TRIS (MM2)

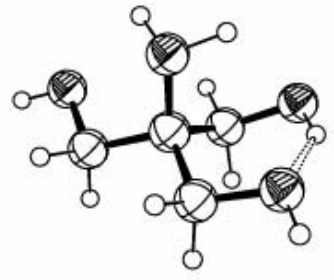

TRIS (MM2)

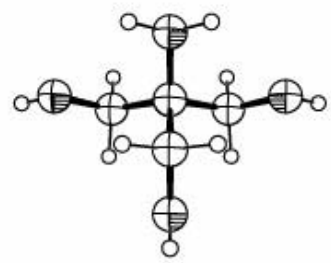

TRIS (MM2)

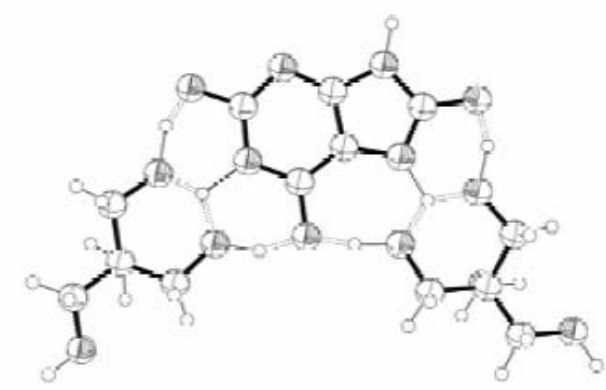

TRIS-HU--TRIS (ZINDO/1)

Figure 5. Selected structures and aggregates as obtained from semi-empirical molecular orbital methods at ZINDO/1 level or from molecular mechanics methods at MM2 level. 
strong hydrogen bond interactions. In fact four $\mathrm{OH}$ groups from the two TRIS molecules behave as hydrogen donors to the three oxygen atoms of $\mathrm{HU}^{-}$, and as hydrogen acceptors for two $\mathrm{NH}$ groups (Figure 5). Note that for the usual setting (12 mg MSU in $5 \mathrm{~mL}$ TMT as specified in the materials and methods section) the overall ratio of TRIS:MSU is 4.0, twice as much as in the TRIS-HU--TRIS aggregate.

\section{Discussion}

\section{Dissolving abilities and their origin}

The amount of MSU (both synthetic and ex vivo) used in the experiments for the determination of the dissolving ability was $12 \mathrm{mg} / 5 \mathrm{~mL}$, which is about two times the solubility at $37^{\circ} \mathrm{C}$ and was chosen for two main reasons. First, to have enough sample to keep the relative weighing error below ca. $0.8 \%$. Second, to be in conditions far from complete dissolution of the crystals and through this to reduce the effect of possible grain size inhomogeneities within the sample. When using at least $12 \mathrm{mg}$ of crystalline sample, a good reproducibility was achieved as expressed by the low value of the relative standard deviation $(0.4 \%)$ obtained from averaging.

The data from this work show good dissolving properties of solutions based on TRIS buffers (TM and TMT) for both synthetic and ex vivo MSU crystals. The high dissolving ability comes from several factors. First, the buffering effect of the media that excludes the precipitation of uric acid $\left(\mathrm{pK}_{\mathrm{al}}=5.5\right)^{23}$ once the $\mathrm{HU}^{-}$anions pass into solution from the crystal surface. Second, the absence of any common ion effect. The PBS buffer, that contains a common ion with respect to $\mathrm{MSU}\left[\left(\mathrm{Na}^{+}\right)=137\right.$ $\mathrm{mmol} / \mathrm{L}]$, is much less effective. Third, the molecules of TRIS (in both their neutral and protonated forms) help solvation of $\mathrm{HU}^{-}$anions via hydrogen bond formation. It has to be recalled that the solubility of MSU in TMT is significantly higher than in pure water, the increase in terms of $\mathrm{DA}_{30}$ being about $13 \%$.

On the other hand, the complex formation ability of the molecules contained in the buffering media toward sodium cations seems to be of less importance as shown by the small or null increase of the DA values in solutions containing SPE and PAMAM when compared to the corresponding values for TMT and pure water, and considering that the expected chelating effects from polyamines are larger than those from TRIS or TRISH+ molecules, at least in the gas phase or in media with low dielectric constants.

TRIS-HU- adduct formation seems therefore more important to explain the high DA values for TM and TMT media. This is confirmed by the results from the molecular modeling analysis which shows that the TRIS and TRISH ${ }^{+}$ molecules have a high affinity for the $\mathrm{HU}^{-}$ anions owing to the formation of many strong hydrogen bonds. The stabilizing contribution has an upper limit of ca $-22 \mathrm{kcal} / \mathrm{mol}$ for each H-bond linkage in the TRIS-HU--TRIS system. This value is reasonable when compared to the computed (gas phase, density functional theory) ${ }^{31}$ formation energy of ca $-27 \mathrm{kcal} / \mathrm{mol}$ for the 6-thiopurine...6-thiopurinate pair having one $\mathrm{N}-\mathrm{H}$...N and two C-H...S hydrogen bond type interactions and for the guanine...cytosine pair in DNA. ${ }^{32,33}$ The adduct formation energies should be much lower once solvent effects are taken into account especially for aqueous systems. The preliminary treatment of solvent (water) effects was carried out at the MM level to model the selected aggregates. Comparing the TRIS-HU--TRIS system calculated without and with solvent effects, it appears that the overall scheme is maintained but, in the presence of bulk water, the two TRIS molecules are located at larger distances from HU-. It has to be noted that $\mathrm{TRISH}^{+}$cations (that are massively present in the buffer at $\mathrm{pH} 7.4$ ) should reasonably give stronger interactions with $\mathrm{HU}$ anions than neutral TRIS molecules do, because of more favorable electrostatic contributions.

\section{Therapeutic applications}

For the incubation time necessary to attain maximum DA values ( $30 \mathrm{~min}$, Figure 2$)$, TRIS buffer has no appreciable toxicity on human chondrocytes (Table 2), possibly due to an oxygen radical scavenger activity stemming from the MAN and TAU co-adjuvants as can be predicted on the basis of previously reported data. ${ }^{34}$ Furthermore, the experiments in this work were conducted with a well-defined volume of dissolving agents and the relative dissolution data were obtained at conditions close to equilibrium (as regards the dissolution process). However one can hypothesize that, in vivo, the dissolving agent could be administered in a continuous flow regime, i.e. joint lavage, that could be more effective owing to two main effects: i) the mechanical removal of the crystalline MSU aggregates; ii) an improvement of the dissolution kinetics if the crystals are exposed to a continuously renewed fresh buffer solution (Figure 2B). Under these conditions, the exposure of the synovial cavity to the buffer solution could be considerably shortened (a few minutes would be sufficient) and toxic interferences would be further reduced.

However, cytotoxicity might not be the only aspect to be considered for a therapeutic application of the buffer solution. The aetiologic rôle of MSU crystals in the development of gout is well established, ${ }^{11,35}$ but the exact mechanism of the inflammatory response is still a matter of debate. Independently from the factors that trigger crystal induced arthritis, the idea to consider the crystal itself the target of the therapeutic strategy is, in our opinion, quite intriguing. To discuss this concept, few data are available from literature. Bennet et al. ${ }^{36}$ observed that injecting a joint affected by chondrocalcinosis with potent calcium chelating agents such as disodium EDTA in order to dissolve CPPD aggregates, a pseudogout attack had been triggered. This paradox was interpreted with the occurrence of a phenomenon of crystal shedding of CPPD deposits from the tissues into joint cavities. The released crystals would be small and more phlogistic than the bigger ones and those anchored to the tissue, in agreement with the finding that the crystal dimensions have much importance on phagocytosis of MSU and CPPD crystals by polymorphonuclear leukocytes. ${ }^{37}$ On the other hand, Bennet et al..$^{36}$ cite that no phlogistic effects are observed when a PBS buffer solution alone is injected. Resuming the above, a therapy based on the direct dissolution of MSU crystals appears possible, but the risk of inflammation and other side effects should be carefully assessed before its clinical application.

\section{Dissolution mechanism and}

\section{microstructure of monosodium} urate monohydrate crystals

Optical microscopy (Figure 3) and the analysis of X-ray diffraction peak widths (Supplementary Figure 1) show that the dissolution of MSU rapidly reduces the crystal size while the grain size $\varepsilon$ remains constant during the process. This means that, during incubation, grains near to the exterior of the crystals (Figure 4) are first dissolved before the underlying grains are attacked, i.e. the dissolution process is not likely to create more crystals than initially present. Regarding microstructure and morphology, the ex vivo extracted MSU material (Supplementary Figure 2B) is similar to its synthetic counterpart, but its grain size $\varepsilon$ is smaller. While the absolute value of the grain size estimate may be in error by $20-25 \%$, the difference is significant and potentially important for the mechanism of crystal growth and dissolution. The reason for the smaller grain size of the ex vivo material remains at present unclear, although an alkaliion compositional variance can be excluded from EDAX evidence. Similar differences have also been reported in earlier studies, e.g. for the average size of the entire crystal which is greater for synthetic than for ex vivo MSU material, ${ }^{38,39}$ and for the decomposition under the electron beam which leaves porous residues with different texture at the submicron-length scale. ${ }^{40}$ It should be remembered, at this point, that the present grain size estimates are based on a non-destructive method 
(X-ray diffraction) and therefore more reliable for a description of the actual microstructure of MSU crystals.

Finally, it has to be recalled that the DA values of TM or TMT for MSU crystals from ex vivo samples from a gouty patient is ca $10 \%$ smaller than the corresponding values for synthetic samples. This might be related to the presence of endogenous proteins or other impurities, linked to the ex vivo crystals. The EDAX and XRD analyses on the ex vivo sample were in agreement with a high purity of MSU as $\mathrm{Na}^{+}$salt, without detectable amounts of other cations $\left(\mathrm{Ca}^{2+}, \mathrm{Mg}^{2+}, \mathrm{K}^{+}\right)$or crystalline impurities. Endogenous proteins linked to MSU crystals are therefore more likely to account for the reduced dissolving ability, either simply because they add up to the total mass of the sample or because they act in some way as a protective coating. Endogenous proteins have been the subject of extensive discussions regarding the mechanism in which MSU provokes the development of gout, ${ }^{9-11,35}$ and recently, such materials have also gained much interest for new theories ${ }^{41,42}$ about the nucleation and growth of crystals where protein-induced clusters are thought to play a central rôle.

\section{Conclusions}

The present study demonstrates that monosodium urate crystals can effectively be dissolved at physiological pH (7.4) and temperature $\left(37^{\circ} \mathrm{C}\right)$ using an appropriate biocompatible buffer solution which shows the way to new therapeutic alternatives in the treatment of gout. Test results for dissolving media of different composition and energy balance parameters obtained from experiment and molecular modeling point out that the dissolving efficiency is based on (a) the buffer action which prevents formation of the more insoluble uric acid, (b) the avoidance of a common ion (Na) effect, and (c) the presence of a molecule (here the buffer itself, TRIS) able to form hydrogen bridge adducts with urate. The addition of dendrimers (PAMAM) to sequester sodium, on the other hand, had no influence on the dissolving efficiency which remained the same as that of pure water. It has to noticed that the comparative analysis that have been performed on different buffers (TM, PAMAM, PBS, PBS+SPE, etc...) showed that TMT was the most versatile and efficient buffer as regards dissolving ability and other important parameters, like osmolarity and $\mathrm{pH}$ (see Dissolving Ability paragraph, under Materials and Methods and under Results sections). These facts are of general interest for work with biomineralizations involving urate.

\section{References}

1. Olmez N, Schumacher HR. Crystal deposition and osteoarthritis. Curr Rheumatol Rep 1999;1:107-11.

2. McCarty DJ. Arthritis associated with crystals containing calcium. Med Clin North Am 1986;70:437-54.

3. Pritchard MH, Jessop JD. Chondrocalcinosis in primary hyperparathyroidism. Influence of age, metabolic bone disease, and parathyroidectomy. Ann Rheum Dis 1977;36:146-51.

4. Sanmartí R, Pañella D, Brancós MA, et al. Prevalence of articular chondrocalcinosis in elderly subjects in a rural area of Catalonia. Ann Rheum Dis 1993;52:418-22.

5. Cini R, Chindamo D, Catenaccio M, et al. Dissolution of calcium pyrophosphate crystals by polyphosphates: an in vitro and ex vivo study. Ann Rheum Dis 2001;60:9627.

6. Khalaf AA, Wilcox WR. Solubility and nucleation of monosodium urate in relation to gouty arthritis. J Cryst Growth 1973;20:227-32.

7. Terkeltaub RA. Gout and mechanisms of crystal-induced inflammation. Curr Opin Rheumatol 1993;5:510-6.

8. Allen DJ, Milosovich G, Mattocks AM. Inhibition of monosodium urate needle crystal growth. Arthritis Rheum 1965; 8:1123-33.

9. Burt HM, Dutt YC. Growth of monosodium urate monohydrate crystals: effect of cartilage and synovial fluid components on in vitro growth rates. Ann Rheum Dis 1986;45:858-64.

10. Ortiz-Bravo E, Sieck MS, Schumacher HR Jr. Changes in the proteins coating monosodium urate crystals during active and subsiding inflammation. Arthritis Rheum 1993;36:1274-85.

11. Terkeltaub R. Update on gout: new therapeutic strategies and options. Nat Rev Rheumatol 2010;6:30-8.

12. Emerson BT. The management of gout. In: Klippel JH, Dieppe PA, eds. Rheumatology, Volume 2. 2nd edition. London: Mosby; 1998. pp 1-8.

13. Pascual E, Sivera F, Yasothan U, Kirkpatrick P. Febuxostat. Nat Rev Drug Discovery 2009;8:191-2.

14. Eachus AC. Pharmaceutical system application of trometamol. Chem Today 1994;12: 24-31.

15. Klug HP, Alexander LE. X-ray diffraction procedures for polycrystalline and amorphous materials. New York: Wiley; 1974.

16. Plumb JA. Cell sensitivity assays: the MTT assay. Methods Mol Med 2004;88:165-9.

17. Dewar MJS, Zoebisch EG, Healy EF, Stewart JJP. Development and use of quan- tum mechanical molecular models. AM1: a new general purpose quantum mechanical molecular model. J Am Chem Soc 1985; 107:3902-9.

18. Anderson WP, Edwards WD, Zerner CM. Calculated spectra of hydrated ions of the first transition-metal series. Inorg Chem 1986;25:2728-32.

19. Aped P, Allinger NL. A molecular mechanics study of cyclopropanes within the MM2 and MM3 force fields. J Am Chem Soc 1992;114:1-16.

20. HyperChemTM Molecular Modelling System, Release 5.1 Pro for Windows, Hypercube Inc., Gainesville, FL; 1997.

21. Mohamadi F, Richards NGJ, Guida WC, et al. Macromodel - an integrated software system for modeling organic and bioorganic molecules using molecular mechanics. J Comput Chem 1990;11:440-67.

22. Burnett MN, Johnson CK. ORTEP-3 for Windows, Oak Ridge National Laboratory, 1998. 32-bit Implementation by Farrugia LJ, University of Glasgow.

23. Finlayson B, Smith A. Stability of first dissociable proton of uric acid. J Chem Eng Data 1974;19:94-7.

24. Wang Zh, Königsberger E. Solubility equilibria in the uric acid-sodium urate-water system. Thermochim Acta 1998;310:23742.

25. Wang Zh, Seidel J, Wolf G, Königsberger E. Dissolution enthalpies of uric acid and uric acid dihydrate. Thermochimica Acta 2000;354:7-13.

26. JCPDS International Centre for Diffraction Data, PDF Data Base. Newtown Square, PA USA, 1997-2009.

27. Mandel NS, Mandel GS. Monosodium urate monohydrate, the gout culprit. J Am Chem Soc 1976;98:2319-23.

28. Chandra AK, Zeegers-Huyskens T. Theoretical study of the acidity and basicity of uric acid and its interaction with water. J Mol Struct Theochem 2007;811: 215-21.

29. Rudman R Eilerman D, La Placa SJ. The structure of crystalline TRIS: a plastic crystal precursor, buffer, and acetylcholine attenuator. Science 1978;200:531-5.

30. Castellari C, Ottani S. Anti-Inflammatory Drugs. V. [Tris-2-hydroxymethyl) methyl]ammonium 2-[(2,6Dichlorophenyl)amino]phenylacetate (TRISH. D). Acta Cryst 1997;C53:482-6.

31. Frisch A, Frisch MJ. Gaussian 98, User's Reference (2nd Edition). Gaussian, Inc., Carnegie Office Park, Building 6, Pittsburgh, PA 15106.

32. Cini R, Corsini M, Cavaglioni A. Supramolecular aggregates of complex cations via unusual purine-purine base pairing in a new organo-rhodium(III) compound containing the antileukemic 
drug purine-6-thione. Synthesis, X-Ray structure of trans(C,N7), $\operatorname{trans}(\mathrm{S}, \mathrm{S})$, trans (P,N7) - [ Rh (C6H6) (H1,H9-H2tp) 2 $(\mathrm{PPh} 3)][\mathrm{Rh}(\mathrm{C} 6 \mathrm{H} 5)(\mathrm{H} 1, \mathrm{H} 9 \bullet \mathrm{H} 2 \mathrm{tp})(\mathrm{H} 9-$ $\mathrm{Htp})(\mathrm{PPh} 3)] \mathrm{Cl} 3 \cdot \mathrm{HCl} \cdot 6 \mathrm{H} 20$, and density functional analysis of the $\{\mathrm{H} 2 \mathrm{tp}$...Htp $\}$ base pair. Inorg Chem 2000;39:5874-8.

33. Defazio S, Tamasi G, Cini R. A molecular orbital study of C-H...Cl-and N-H...Clhydrogen bonds. Inferences on selected metal complexes and on ClC Cl-channels. C R Chim 2005;8:1584-609.

34. Dahlgren C. Effect of different inhibitors on the intracellularly and extracellularly generated chemiluminescence induced by formylmethionyl-leucyl-phenylalanine in polymorphonuclear leukocytes. Cellular response in the presence of mannitol, benzoate, taurine, indomethacin and NDGA. J
Biolumin Chemilumin 1991:6:29-34.

35. Kam M, Perl-Treves D, Caspi D, Addadi L. Antibodies against crystals. FASEB J 1992;6:2608-13.

36. Bennet RM, Lehr JR, McCarty DJ. Crystal shedding and acute pseudo-gout: an hypothesis based on therapeutic failure. Arthritis Rheum 1976;19:93-7.

37. Schumacher HR, Fishbein P, Phelps P, et al. Comparison of sodium urate and calcium pyrophosphate crystal phagocytosis by polymorphonuclear leukocytes. Effects of crystal size and other factors. Arthritis Rheum 1975;18:783-92.

38. Paul H, Reginato AJ, Schumacher HR. Morphological characteristics of monosodium urate: a transmission electron microscopic study of intact natural and synthetic crystals. Ann Rheum Dis
$1983 ; 42: 75-81$.

39. McGill NW, Hayes A, Dieppe PA. Morphological evidence for biological control of urate crystal formation in vivo and in vitro. Scandin J Rheumatol 1992;21:2159.

40. Pritzker KPH, Zahn CE, Nyburg SC, et al. The ultrastructure of urate crystals in gout. J Rheumatol 1978;5:7-18.

41. Horn D, Rieger J. Organic nanoparticles in the aqueous phase-theory, experiment, and use. Angew Chem Int Ed 2001;40:433061.

42. Niederberger $M$, Cölfen $H$. Oriented attachment and mesocrystals: non-classical crystallization mechanisms based on nanoparticle assembly. Phys Chem Chem Phys 2006;8:3271-87 